nutum before the manual operation was performed, to guard against the risk of further bleeding. Obliquity of the uterus, to a considerable degree, existed, on which account I had the patient placed, to labour, on the back. The aid derived from the regulating bandage was very great; and when it was drawn tight, the fundus and body of the uterus were raised from the anterior dependant position, and retained in the line of the axis of the inlet of the pelvis.

[To be continued.]

\section{ON THE PLEA OF INSANITY IN CRIMINAL CASES.}

By J. G. Davey, M.D., Northwoods, Bristol.

[Real at the Meeting of the Bath and Bristol Branch, Fel. 21st, 1850.]

Wiтris these past few weeks there have appeared in the daily papers the recital of the particulars of the several trials of Abraham Baker, Charles Broadfoot Westron, and Thomas William John Corrigan; the first named was arraigned for the murder of one Naomi Kingswell, the second for that of Mr. George Waugh, and the third for the murder of his wife, Louisa Corrigan. In each case the "plea of insanity" was mooted on the part of the defence. These three men were plainly enough insane; they had been so, I believe, for some time before the commission of the sereral acts of violence recited. The fact of three lunatics being at large, and living, day by day, in the enjoyment of all the privileges of sane men, is greatly to be deplored. There is good reason to believe that insanity is so little understood, and, moreover, that the early indications of the disease are so constantly unheeded, even when understood, by the friends and relatives of hin aftlicted, that society may quite expect to continuc to suffer the consequences of the perverted and unrestrained passions of the madman, permitted as he is to move about in the world, so little heeded or cared for. With reference to the poor men above named, I hesitate not to affirm that a more positive act of cruelty and neglect can hardly be conceived than that one which would leave either of them to his own free will or in a position to be led by the capricious and disordered emotions and feelings which prey on him and render him but their mere instrument for good or for evil. The frequency of acts of personal violence, the never-ending suicides and homicides, the oft told tale of crime and licentiousness to be referred to the disordered mind, the climax, so to speak, of insanity, seem to compel us, as medical men, to call the attention of the public and the legislature to the means whereby so much of evil may be averted, and so large a proportion of human misery be got rid of. I have thought that the cases of Baker, Westron, and Corrigan may supply us with some valuable clinical facts, whereby to demonstrate the ignorance of, and inattention to the subject of insanity; and that these may be considered of such a nature and tendency as to excuse me trespassing some ten or fifteen minutes on your time and patience this evening.

1. Abraham Baker, as is known, shot his fellow servant, Naomi Kingswell, a respectable young woman, to whom he had been for a long time greatly attached. Baker was evidently a half-witted fellow, not a little crazed in the matter of religion, and full of extravagance about things both temporal and eternal. Without any of the ordinary antecedents of crime, and without a seeming motive, he strays out one fine evening in search of a doublebarrelled pistol, from the purchase of which, however, he seems to have been dissuaded; he bought one with a single barrel, and returning home, pursues his avocations, as usual. The next morning (Sunday) he goes out, but not to church as was his custom; it seems he rambled about in an abstracted manner, and returning home he presently finds himself talking in an ordinary manner, and on common-place subjects, with two of his fellow servants, one of them being Naomi Kingswell. Baker, after standing mute and motionless for two or three minutes, quietly raises his right hand and discharges the pistol at the poor unsuspecting girl named. She falls dead, whilst he makes no effort to escape, but remains a quiet spectator of her corpse. A policeman is called from the street, who takes Baker into custody. I should tell you that a letter written by him to his father before the fatal occurrence contains these words: "this may be the last time I shall have to write to you;" the writer adds, "I will leave all my things for you and mother." The poor young man evidently premeditated suicide. Baker was defended by Mr. Cook, who very properly remarked that " there was nothing to shew that, up to the period of the death of the unhappy young woman, the prisoner did not bear an irreproachable character" $\rightarrow$ circumstance in itself incompatible with all the ordinary antecedents of one rightly charged with the appellation of murderer. "In all cases of great crime", remarked $\mathbf{M r}$. Cook, "such as the present, where a party was charged with wilful murder, they were generally able to trace the advance of crime, step by step, from small beginnings till they came to the accomplishment of the great offence." Mr. Cook proceeded thus: "Maddened and distracted, he went to the shop of the gunsmith, and asked for a doublebarrelled pistol; and was not that evidently for the object of sacrificing his own life as well as that of the young woman's-for the purpose of discharging one bullet at the young woman, and the other at himself ? Then did not the letter written by him to his father show that his mind was disturbed and overcome, and his reason abandoned! The assertion that it was the last letter be should ever write was indicative of an intention of self-destruction; and supposing he had in that unhappy moment sacrificed his own life, would not they-would not all the worldwould not the inquest have said that he died when labouring from the effects of temporary insanity? If so, was it not now within the province of the jury to say-considering his acts from beginning to cnd, the previous state of his affection for the young woman, his known honesty of character, and his religious principles-that reason was absent from her seat, and that he was not a person who was at that moment in a position to be answerable for what he did? Did he not act as a man deroid of reason at the time when the fatal hour arrived, and the life of the young woman was takeu? He did not attempt to escape, but stood there over the bleeding body of his rictim, wanting the reason and sense to control, and the judgment to guide him. Was it not rather the act of a man without reason, who knew not the act be had done, or the responsibility he was under for so serious and grave an offence. A policeman came, and so terminated this fatal tragedy. It was not because the prisoner was present there in sound mind, or was able, soon after the occurrence, to make the statement he did, that he was, therefore, of sound mind at the time of the commission of the offence. It was known in the annals of history in these cases, that frequently the very shockthe very act of the man in committing so gross an offence -brought him back again to reason, and reason, taken for a time by temporary insanity, again resumed her seat. He implored and besought them, therefore, to consider that the issue was not whether the prisoner committed the act, but whether he was a responsible person. Let them look at the superior conduct of the man's life, and the object who had fallen his victim; to his affection for that object, his conduct at the time, and the whole of the circumstances, and he thought they would be enabled in humanity-which was one of the attributes they possessed and used-to any that at the time the dreadful act was committed he was not in such a state as to enable him to have control over his actions, and to acquit him on the ground of insanity, when he would not be discharged, but would be disposed of in such a way as would meet the ends of justice. He besought them, therefore, to stand between the prisoner and the executioner, to consider all the circumstances, and if, under the direction of his lordship, they could do so, to give the prisoner-he would not say the benefit of a doubt, but to come to the conclusion he had suggested; and he was sure 
it would be a pleasure to them to do so, and that in times when this season of excitement was over they would be onabled to appeal to their consciences, and, in the hours of quiet, to say that they had done justice between the Crown and the prisoner."

The good effects on the jury of Mr. Cook's truthful, eloquent, and humane appeal were frustrated by the remarks of the presiding judge, who contended that because the "weapon was prepared, and the wound inflicted in the presence of a witness", then must Baker have been sane and responsible. This very learned judge declared, also, that the only question was whether, at the time he did it, he was in a state of insanity to such a degree as not to knor what he was about. "It must be shown", said he, "that Baker was insane, and that from disease of the mind he was incapable of judging between right and wrong." Now, nothing is better known, or can be with more propriety insisted on, than that the majority of those bond fide mad, and therefore irresponsible inmates of both private and public asylums, know what they are "about" as well as they ever did, or as completely as ourselves at this very moment; and, what is more, that the insane, i.e. the irresponsible, are, as a rule, not only quite capable of judging between right and wrong, but manifest, on very many occasions, the most accurate appreciation of the merits and demerits of a question. The Bench and the Bar will not be taught. Lawyers, with but few exceptions, will persist in it that they are sufficiently well in. formed in medical matters to decide the most complex questions of psychological science. The legal profession has yet to learn that insanity is a disorder, in nine cases out of ten, not of the intellectual faculties, but of the active moral feelings; and that these latter it is which, both among the sane and the insane, give to the former their individuality, i.e., their specific tendency and qualities.

The eloquent words of the late Lord Erskine might have sared to the country the ignominious death of the young man Baker ;* that they negative the assertions of the presiding judge you will admit. "I have found the insane not only possess the most perfect knowledge and recollection of all the relations they stood in towards others, and of the acts and circumstances of their lives, but to have been remarkable for their subtlety and acuteness." Again, "Reason is not driven from her seat in maniacal disorders, but distraction sits down upon it along with her, and holds her trembling upon it, and frightens her from her propriety." The madness of Zuleka is similarly treated by Moore. In the poet's charming description of his much loved heroine, he has these words :-

"The mind was still all there; but turned astray A wand'ring bark, upon whose pathway shone

All stars of heav'n save the guiding one."

"There is no hope", pitifully exclaimed Coleridge ; "for my case is a species of madness, only that it is a derangement and utter impotence of the volition, and not of the intelloctual faculties."

2. Westron, who, it will be remembered, has just been tried for the murder of Mr. Waugh in a public thoroughfare in Iondon, and virtually acquitted on the ground of insanity, though after a somewhat lame fashion, inherited his disordered mind from his father; who, in the words of $\mathrm{Mr}$. Rodham, a solicitor, and a witness on the trial, destroyed himself by cutting his throat. We are told, moreover, that he (Westron) was always of a morose and sullen disposition, that his uncle destroyed himself, and that there was a good deal of insanity in the family. It is erident enough that poor Westron had been suffering from active maniacal disorder, complicated with various delusions since July 1854; and that, moreover, so long back as three jears he suffered under great mental disturbance; when, as Te are informed by Mr. F. Flower (surgeon), no rational answer could be obtained to any question that was put to him. It is right I should add, that then Mr. Flower very properly advised that Westron should be placed in restraint; but so

- Baker was executed at Winchester \& fow weeks since. desirable a proceeding was neglected. The medical eridence as to the insanity and consequent irresponsibility of this poor man was farther corroborated by Dr. Synuott; and because this gentleman admitted, in his cross-examination, that " many lunatics would be aware perfectly well that the act [of murder] was a wrong one," Mr. Clarkson hesitated not to incur the very serious responsibility of declaring that "the case had failed on the part of the defence," and that "nothing had been shown to justify the jury in coming to the conclusion that, at the time he committed the dreadful act, he was not perfectly aware what he was doing, and was therefore fully responsible."

Now, gentlemen, there are two or three features in this case which demand our most serious attention. One is, that a lunatic labouring under homicidal mania should have been allowed for some three years to have all that liberty which belongs to a sane man; that one so much and seriously afflicted should have had the opportunity for so long a period of injuring his fellow-man with impunity - of introducing pain and sorrow and poverty to the domestic hearth-of depriving childhood of its support, and parents of their much-loved offspring; and of breaking up those social ties and endearing sympathies without which life becomes a blank, and existence a painful monotony. Again; such an amount of inattention and neglect tend to the aggravation of the patient's sufferings : and, in case of an ultimate recovery, how deeply must he regret those acts of fraud or violence which he may have committed under the influence of disease.

With regard to Mr. Clarkson's misplaced energy, I can here only enter my protest against the principles involred in his statement, as above quoted. If Mr. Clarkson, or any other lawyer in Christendom, will insist on it that all those madmen who are perfectly aware what they do, or, in legal phrase, "can distinguish right from wrong", shall be held responsible for their acts; then I say, the plea of insanity becomes a dead letter, a mere idle apology. It is high time that Lord Hale and his prejudices were forgotten in matters of medical jurisprudence. We, as medical philosophers, unlike the professors of old and musty precedents, begotten in ignorance and conceived in selfishness, are not content to stand for ever still, and vainly stem the rise and progress of truth and humanity: we would advance with the times, and forget, if it be possible, that revenge did ever blot the statute-book of this great empire; bearing well in mind that this deprivation of intellect, as understood by the judges in their famous replies to the questions of the peers, exchanged now some ten years since, and as echoed by Mr. Clarkson, "cannot be taken in a literal sense of the words," " because no such madness ever existed". "It is idiocy alone which places a man in this helpless condition; where, from an original organisation, there is the human frame alone, without the human capacity." (Erskine.) The execution of such an individual, exclaims the late Sir E. Coke, "would be a miserable spectacle, both against law, and extreme inhumanity and cruelty, and no example to others." Perhaps Mr. Clarkson may be inclined to attach some importance to the recorded opinions of these once famous lawyers: more of such men at this day would lead to the right appreciation of the plea of insanity, and the aroidance of the punishment of insane persons.

The intelligence and humanity of the jury in this case must not be forgotten; for, notwithstanding the advice of Mr. Clarkson, and not less the counsel of the learned judge, they so far passed by the suggestion to return an unqualified verdict of "wilful murder" against Westron, that they "recommended the prisoner to mercy, on account of his strong predisposition to insanity". The circumstance I regard as a happy omen for the future-as an indication of the growing intelligence and independence of juries; for, as Mr. Justice Wightman remarked, "the jury, who were the best judges in such a case, had come to the conclusion that, although he might be insane on some points. he knew right from wrong, and they had recommended him to mercy." The idea of partial insanity and partial responsibility is herein suggested; but a man is either sane and 
responsible, or insane and irresponsible: no half-and-half measures can suffice for justice' sake.

3. With regard to the case of Corrigan, we learn that, on the night of Christmas-day, he, with his wife, joined a party of friends, and drank freely. After the women had retired for the night, the men sat up drinking. It appears that the consequences of this debauch, acting on the brain and nervous system of Corrigan (already rendered susceptible by an old injury to the brain, by habits of drunkenness, and former attacks of delirium tremens), were such as to excite the attention of his friends. He appcared "lost" and "strange", "wild about the eyes", and "vas dreadfully wild and excited". It was given in evidence, that he looked quarrelsome and cross, and complained that he did not feel very well. Corrigan is described as a man naturally, and under ordinary circumstances, of mild manners and amiable conduct, and as being seldom out of temper. His conduct to his wife is declared to have always been kind and forbearing, even under provocation. "The deceased", observed a neighbour and a witness, "was occasionally violent, but the prisoner always behaved very kindly to her." The evidence goes to show that the maniacal symptoms increased in intensity; and presently, rushing into the room occupied by his wife, he stabbed her to the heart, and she expired. And farther: "after the occurrence, the prisoner was quite passive. He stood fixed, and was led down stairs, and given into custody. He afterwards appeared much affected, and burst into tears." From letters written by the prisoner during his confinement, the irritable and distracted state of his feelings are painfully shown.

The defence of this unhappy man was very ably conducted by Mr. Ballantine, who said, "that it was clear from the evidence that the prisoner was on good terms with his wife almost up to the moment of the unhappy occurrence, and that the act of destruction had been committed under some uncontrollable impulse, and could only be accounted for by the supposition that the prisoner was not in his right senses at the time the act was committed."

The summing up of Mr. Justice Wightman deserves to be chronicled; who, in spite of the antecedents of the prisoner, and in the face of the important facts bearing on the history of the nature of the case, a few of which $I$ have here brought to your attention, and in direct opposition to psychological science, thus expressed himself, viz.: "The only question, then, was whether he was in such a state of mind as would render him responsible for his actions; and this certainly was a most important question to be considered. It was his duty to tell them that, before they could come to the conclusion that the prisoner was not re. sponsible on the ground of insanity, they must be satisfied that, at the time the act was committed, the prisoner was labouring under such a defect of reason as not to know the nature and quality of the act he was committing, and also that he was not aware he was doing wrong; and it appeared to him that there was no evidence in this case that would justify the jury in coming to either of these conclusions. The prisoner appeared to have acted in a perfectly rational manner up to the very moment of the fatal occurrence; and, although it was extremely probable that the act was committed under some sudden feeling of excitement, possibly aggravated by the drink he had taken, it would be calculated to lead to very dangerous consequences indeed if a man under such circumstances was not to be held responsible for his acts."

You are aware that Corrigan is found guilty of the wilful murder of his wife; and the probabilities are that he, like very many more insane persons have been, will be sacrificed to the laws of his country.* A painful thcught this-one to which the mind must fail to be recognised.

The foregoing cases are in themselves sufficient to convince any impartial observer that such are the inconsistencies and defects of the "plea of insanity", such the contradictions among members of the legal profession in reference

- Since the abore was written, Corrigan bas been reprieved. thereto, that the time has come when the country can no longer be satisfied with the present state of things; and when the famous replies of the judges to the five carefully digested questions of the peers, prepared and exchanged in 1842 , for the purpose of placing the plea of insanity in criminal cases on a right and just footing, and in harmony with the facts and principles of psychological science, must be revised, and made subordinate to the requirements of truth and the instincts of a common humanity; and which together should afford all due protection to society at large, and preserve the lunatic from a revengeful and oppressive law.

\section{CASE OF PLACENTA PREVIA.}

By R. EI.SD.ILE, Esq., Moulton, Spalding.

MRs. WADE, aged 44 years, the mother of fifteen children, in the family way for the sixteenth time, had spoken to a nurse who occasionally acts as a midwife to attend her. As I was riding past the house (about three miles distant from my own), the latter requested I would come should she send for me, as, from the repeated loss of blood the woman had had for the last fortnight, she was afraid something was wrong.

Upon further inquiry, I found that, early in the morning of the 9th of the present month (the day upon which this conversation took place), the poor woman had a very great loss, so much that, to use her own expression, "she was nearly drowned". After explaining the serious nature of the case, I determined upon instituting an examination at once.

The woman was at the full time of uterine gestation. I found the vagina containing a large quantity of coagula. and, upon its removal, there was a slight trickling of fluid blood going on; the os uteri was dilated to about the size of half a crown, hard, resisting, and undilatable. Upon passing my finger into the cavity of the womb, I could feel nothing but the placenta, which appeared to be entircly attached to the cervix. I found the resistance so great that it was impossible to introduce more than two fingers with safety; so that I determined to wait. I folded up a napkin into the form of a plug, which I carried up to the mouth of the uterus; and left the case for two hours, going to a neighbouring patient's, close by, leaving strict orders that, upon any alteration taking place, to send to me immediately.

I was returning, when I met the husband coming to tell me his wife was worse. Upon examining, I found blood trickling beside the plug, which was saturated: still no great quantity had been lost; and the time given had had a very good effect upon the state of the os uteri, which had become thin and dilatable.

Upon again examining, I found that the placenta was not entirely attached over the os uteri, but that with the pains a considerable portion was forced down into the vagina; and, upon carrying my fingers upwards and forwards, I felt the membranes, with the shoulder of the child presenting. I determined upon delivery at once, as the woman's position was becoming highly dangerous, and the state of the uterus was not particularly unfavourable for turning.

I proceeded to remove all the placenta I could get hold of. The uterine action was considerable, and with every pain a frightful gush of blood took place. I steadily but firmly persevered in my determination to turn; I succeeded with some little difficulty in getting hold of a foot, which I brought down, and attached a piece of tape round the ankle; and, by making traction, I easily brought down the other extremity, so as completely to plug the vagina. As the woman was a good deal exhausted, I deemed it advisable to allow the child to remain in this position while the mother partook of some gruel I had previously caused to be made, and to which I added some brandy. This she took with very good effect; and in a short time I completed delivery. I then introduced my hand into the uterus, and removed the remaining portion of the placenta, when contraction speedily and completely followed. During the 